\title{
Ergonomic Assessment of Upper Limbs of Workers Involved in Vegetable Cultivation
}

\author{
Swapnali Borah* and Nilakshi Borah \\ College of Community Science, Central Agricultural University, \\ Tura, Meghalaya - 794005, India
}

K e y w o r d s
Weeding, Vegetable
cultivation, Rapid
upper limb
assessment, Rapid
Entire Body
Assessment,
Ergonomics,
Musculoskeletal
Disorders
Article Info
Accepted:
26 April 2020
Available Online:
10 May 2020

Keywords

Weeding, Vegetable cultivation, Rapid upper limb

Entire Body

Assessment,

Disorders

Accepted:

26 April 2020

10 May 2020

\section{A B S T R A C T}

The study was conducted among 80 female and 20 male farmers from two villages of namely Aminda Rangsagre and Aminda Simsanggre of Gambegre block of West Garo Hills who are doing vegetable cultivation were selected purposive sampling procedure. The study was limited to only weeding activity as women participation is more in this activity. RULA and REBA assessment tool were used to analyze the musculoskeletal injury risks of the farm workers. Assessment is carried out using worksheet. The results of RULA assessment determined that most of female workers task need further investigate and change soon as female participation was more in weeding activity. REBA assessment showed that workers working in unnatural posture which can develop the possibilities of postural MSDs, therefore task needs investigation and implement change. Therefore it was concluded that lack of ergonomics awareness and lack of use of improved tool can lead to task risk and increase in work related health risk and injuries.

\section{Introduction}

Agriculture is the backbone of the country that people learnt to practice as a means of living and a way of life. It is the central part of any economy either it is developed or developing. As India is agriculture based country where nearly 70 percent of the population in rural areas depends directly or indirectly on the income derived from agriculture (Mahendra Dev, 2011).
In rural India, above 84 percent of women who depend on agriculture for their livelihood. Among them about 33\% are cultivators and about $47 \%$ percent are agricultural labourers (Rao, 2006). The daily work schedule of rural women is very challenging and laborious and women are working every day for 8-9 hours in agriculture and 4 hours in household activities. Also women play a farm significant and key role in production of vegetable (Kumari, Anuradha 
Ranjan and Laxmikant, 2015). Women as farmer or farm workers, take part in some activities such as seeding, weeding, transplanting, plant protection, fertilizer application, processing, harvesting, winnowing, selling, storing, etc. (Sudharani and Raju, 1991). Women are also likely to collect fuel wood from a field, which is being used as a main fuel source for cooking (Gupta, M.P, 2005).

In Meghalaya above 83 percent of total population mainly depends on Agriculture for their livelihood (Solomon et. al 2006). They are mainly depends on vegetable cultivation than other crop cultivation because of hilly region and the favourable agro climatic condition. Both male and female are involved in all the activities of vegetable cultivation but in some activities like weeding, sowing, cleaning, carrying etc where female participation is more than male. All these activities performed by rural farm women involved in vegetable cultivation were also affected by some work related hazards, pain in back, lower limb and other body parts due to adoption of unnatural body posture, continuous working pattern, and repetitive motion of upper \& lower limb and use of primitive technologies. Therefore this study was envisaged for Assessment of Upper Limb of Women Worker involved in Vegetable Cultivation.

\section{Materials and Methods}

In order to determine the samples for this study, 80 female and 20 male farmers from two villages namely Aminda Rangsagre and Aminda Simsanggre of Gambegre block of West Garo Hills who are doing vegetable cultivation were selected purposively. The study was limited to only weeding activity as women participation is more in this activity and faced lots of physical hazards and Work Related Musculo Skeletal Disorders
(WMSDs). To analyze the musculoskeletal injury risks, Rapid Upper Limb Assessment (RULA) and Rapid Entire Body Assessment (REBA) were done.

\section{RULA assessment method}

Rapid Upper Limb Assessment (RULA) is an assessing tool which was developed for ergonomics analysis of workplaces where work- related upper limb disorders are observed (McAtamney and Corlett, 1993). This assessment tool provides a rapid evaluation of postures of upper limbs, neck, and trunk along with muscle purpose and the extraneous loads practised by the body in the working environment. After complete posture analysis ranking of each posture is given by a score. Based on final score, four action levels will indicate the necessary actions to be taken to ease the risks of injury due to physical loading on the worker. Various action levels of RULA investigations based on the final score as shown in Table 1.

\section{REBA assessment method}

Rapid Entire Body Assessment is an ergonomics tool to evaluate whole body postural MSD and risks associated with job tasks. It is a single page worksheet developed by Hignett and McAtamney in the year 2000 which is used to evaluate required body posture, forceful exertions, type of movement or action, repetition and coupling. In this assessment tool body parts are divided into sections and each part is scored according to its range of movement. Higher scores are given to the body parts where presence of risk factors are more and lower scores are specified to those where occurrence of risk factors are minimum. The REBA score is in the range $1-15$, corresponding to risk levels negligible (1), low (2-3), medium (4-7), high (8-10) and very high (11-15). 


\section{Results and Discussion}

\section{Assessment of upper limb by using rula for female workers}

Table 2 and Fig 1 showed that more than 28 percent farm women workers engaged in weeding activity were at high risk and needs investigation and immediate change, whereas 54 percent of female respondents were found at medium risk levels. The results showed that activity needs to further investigate and change soon. While doing weeding activity female workers involvement is more than male and having pain in neck, trunk and upper limb due to prolonged squatting position at the time of weeding operation which may results in musculoskeletal disorders. Dalkilinic et al., (2002) evaluated the status of musculoskeletal disorders by RULA and showed that with an increase in RULA score, the occurrence of musculoskeletal disorders increases. Ansari and Sheikh in the year 2014 revealed that majority of scale industry workers were at high risk levels and required immediate change.

\section{Assessment of upper limb by using rula for} male workers

After assessment of RULA (Table 3 and Fig 2) it was found that 35 percent of male workers at high risk levels and needs investigation and immediate change, whereas 15 percent male respondents were at medium risk that were engaged in weeding activity which required further investigation.

In a different study on work posture improvement of strawberry farmers in Bali using RULA analysis recommended changing from bending work posture using the old tool into standing work posture using new hole maker or digger (Yusuf et al., 2016).

\section{Assessment of upper limb by using REBA for female workers}

REBA assessment results are presented on Table 4 and Fig 3 and was observed that most of the female workers were working in unacceptable posture at high risk levels. Analysis of the data showed that 54 percent of workers were working at high risk level, as female workers continuously doing weeding activity in same posture and they suffer from the MSDs related to neck, trunk and wrist. It was suggested to do investigation and implement change. In a different study conducted among drilling operation worker while using REBA tool, the results showed that majority were working in acceptable posture and a necessary change may be required. The workers were working at high risk levels (about 53percent) and required a necessary action soon with high physical sprain in their wrist, trunk and neck (Ansari and Sheikh 2014). Above 27 percent of the workers involved in weeding activity were at medium risk level and needs further investigation and change soon. More than 18 percent of the female workers recommended that change may be needed in their working body posture.

\section{Assessment of upper limb by using REBA for male workers}

Results of REBA for male worker engaged in weeding activity under vegetable cultivation presented in Table 5 and Fig 4. It was observed that 40 percent of the male workers were at high risk levels and their neck, trunk, legs under high physical risk which indicate further investigation and implementation of change. Again data shows that 25 percent male respondents who engaged in weeding activity are at medium risk level and needs a further investigation and change soon. But 35 percent of the male workers are working in low risk level and change may be needed. 
Table.1 Action Level and Final Score according to RULA

\begin{tabular}{|c|c|c|}
\hline Action Level & Final Score & Proposed Action \\
\hline $\mathbf{1}$ & $1-2$ & Posture is Acceptable \\
\hline $\mathbf{2}$ & $3-4$ & Further investigation is needed and changed may be needed \\
\hline $\mathbf{3}$ & $5-6$ & Investigation and changes are required soon \\
\hline $\mathbf{4}$ & 7 & Investigation and changes are required immediately \\
\hline
\end{tabular}

Table.2 Categorization under RULA Level of Female respondents engaged in weeding activity of vegetable cultivation

\begin{tabular}{|l|c|c|c|c|}
\hline RULA Level & $\mathbf{0}$ & $\mathbf{1}$ & $\mathbf{2}$ & $\mathbf{3}$ \\
\hline RULA Score & $1-2$ & $3-4$ & $5-6$ & 7 \\
\hline Risk Level & Negligible & Low & Medium & High \\
\hline Required Action & $\begin{array}{c}\text { Acceptable } \\
\text { posture }\end{array}$ & $\begin{array}{c}\text { Further investigation, } \\
\text { changed may be } \\
\text { needed }\end{array}$ & $\begin{array}{c}\text { Further } \\
\text { investigation, } \\
\text { change soon }\end{array}$ & $\begin{array}{c}\text { Investigation and } \\
\text { changes are required } \\
\text { immediately }\end{array}$ \\
\hline $\begin{array}{l}\text { Percentage of } \\
\text { Female Workers }\end{array}$ & - & 17.5 & 53.7 & 28.7 \\
\hline
\end{tabular}

Table.3 Categorization under RULA Level of Male respondents engaged in weeding activity of vegetable cultivation

\begin{tabular}{|l|c|c|c|c|}
\hline RULA Level & $\mathbf{0}$ & $\mathbf{1}$ & $\mathbf{2}$ & $\mathbf{3}$ \\
\hline RULA Score & $1-2$ & $3-4$ & $5-6$ & 7 \\
\hline Risk Level & Negligible & Low & Medium & High \\
\hline Required Action & $\begin{array}{c}\text { Acceptable } \\
\text { posture }\end{array}$ & $\begin{array}{c}\text { Further investigation, } \\
\text { changed may be } \\
\text { needed }\end{array}$ & $\begin{array}{c}\text { Further } \\
\text { investigation, } \\
\text { change soon }\end{array}$ & $\begin{array}{c}\text { Investigation and } \\
\text { changes are required } \\
\text { immediately }\end{array}$ \\
\hline $\begin{array}{l}\text { Percentage of } \\
\text { Male Workers }\end{array}$ & - & 50 & 15 & 35 \\
\hline
\end{tabular}

Table.4 Categorization under REBA Level of Female respondents engaged in weeding activity of vegetable cultivation

\begin{tabular}{|l|c|c|c|c|c|}
\hline REBA Level & $\mathbf{0}$ & $\mathbf{1}$ & $\mathbf{2}$ & $\mathbf{3}$ & $\mathbf{4}$ \\
\hline REBA Score & 1 & $2-3$ & $4-7$ & $8-10$ & $11-15$ \\
\hline Risk Level & Negligible & Low & Medium & High & Very high \\
\hline Required Action & $\begin{array}{c}\text { None } \\
\text { necessary }\end{array}$ & $\begin{array}{c}\text { Change } \\
\text { may be } \\
\text { needed }\end{array}$ & $\begin{array}{c}\text { Further } \\
\text { investigation } \\
\text { change soon }\end{array}$ & $\begin{array}{c}\text { Investigate and } \\
\text { implement } \\
\text { change }\end{array}$ & $\begin{array}{c}\text { Implement } \\
\text { change }\end{array}$ \\
\hline $\begin{array}{l}\text { Percentage of } \\
\text { Female Workers }\end{array}$ & - & 18.7 & 27.5 & 54 & - \\
\hline
\end{tabular}


Table.5 Categorization under REBA Level of Male respondents engaged in weeding activity of vegetable cultivation

\begin{tabular}{|l|c|c|c|c|c|}
\hline REBA Level & $\mathbf{0}$ & $\mathbf{1}$ & $\mathbf{2}$ & $\mathbf{3}$ & $\mathbf{4}$ \\
\hline REBA Score & 1 & $2-3$ & $4-7$ & $8-10$ & $11-15$ \\
\hline Risk Level & Negligible & Low & Medium & High & Very high \\
\hline $\begin{array}{l}\text { Required } \\
\text { Action }\end{array}$ & $\begin{array}{c}\text { None } \\
\text { necessary }\end{array}$ & $\begin{array}{c}\text { Change may } \\
\text { be needed }\end{array}$ & $\begin{array}{c}\text { Further } \\
\text { investigation } \\
\text { change soon }\end{array}$ & $\begin{array}{c}\text { Investigate and } \\
\text { implement } \\
\text { change }\end{array}$ & $\begin{array}{c}\text { Implement } \\
\text { change }\end{array}$ \\
\hline $\begin{array}{l}\text { Percentage of } \\
\text { Male Workers }\end{array}$ & - & 35 & 25 & 40 & - \\
\hline
\end{tabular}

Fig.1 Percentage of Female workers under RULA level

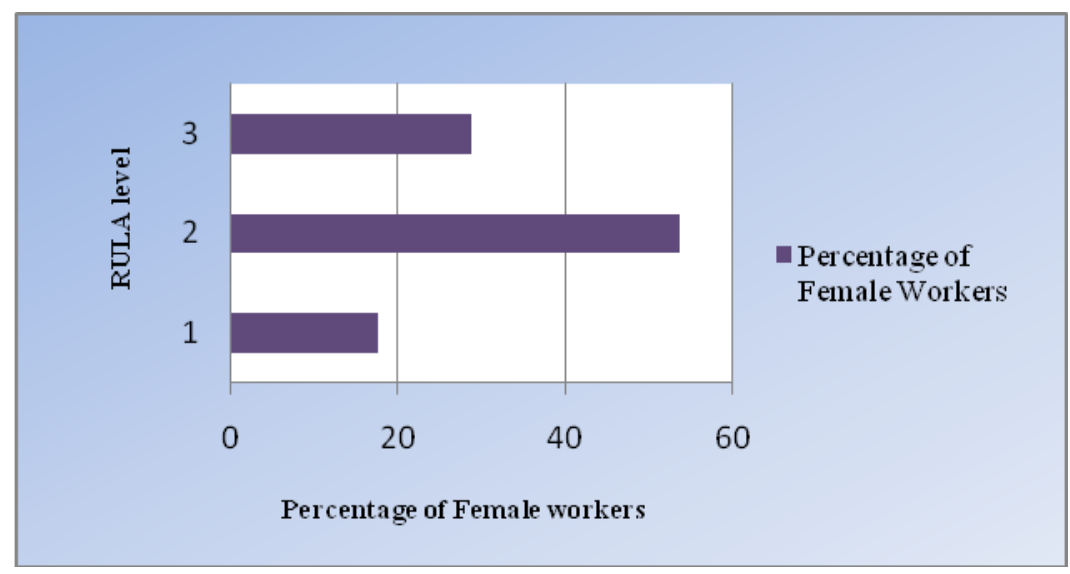

Fig.2 Percentage of Male workers under RULA level

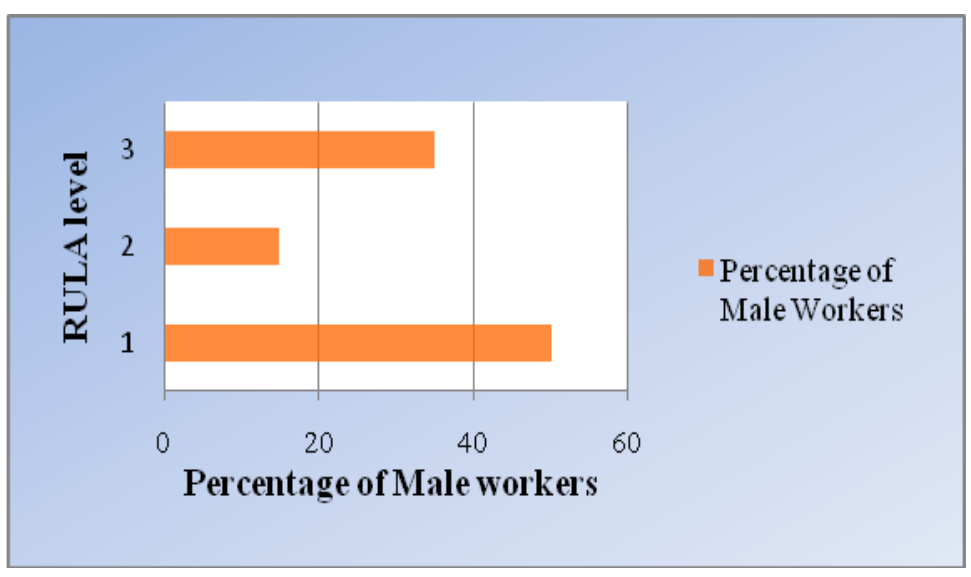


Fig.3 Percentage of Female workers under REBA level

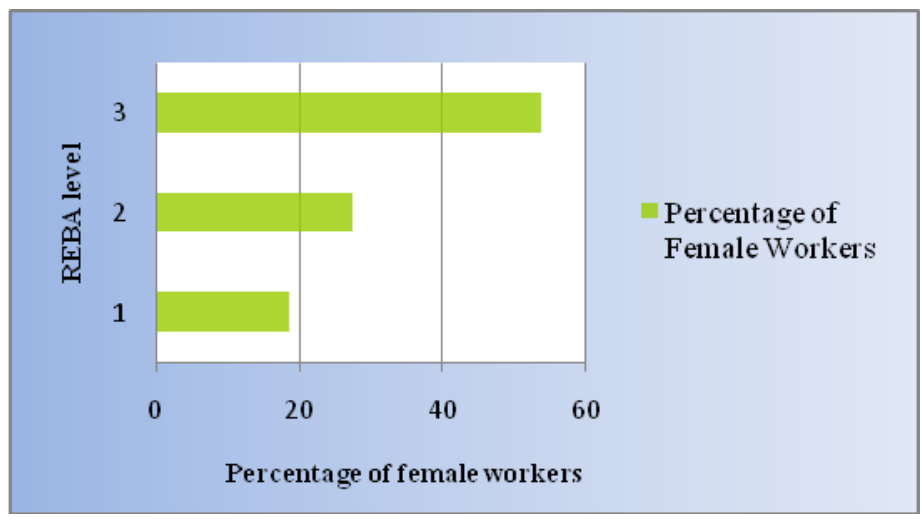

Fig.4 Percentage of Male workers under REBA level

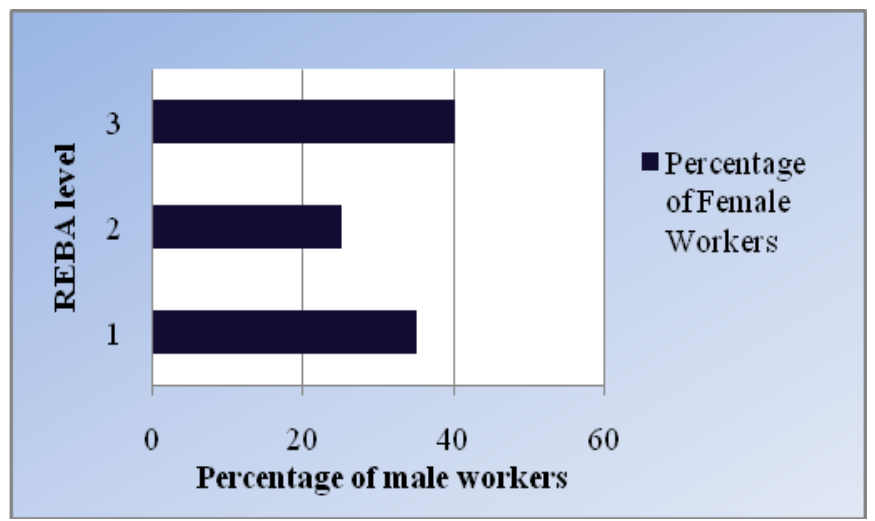

It is concluded that after assessment of upper limb of workers involved in weeding activity while doing vegetable cultivation found that weeding activity was monotonous, tedious and repetitive in manner and involvement of women was more than man and women are more susceptible than man in case of WMSDs. Grooten et al., (2007) stated that sustained and monotonous work was a strong risk factor for musculoskeletal problems. The workers engaged in vegetable cultivation work constantly 6-8 hours in a squatting posture during weeding operation. These postures have resulted in pain in different parts of the body i.e. neck, lower back, trunk, wrist, shoulders etc and also unacceptable working posture may leads to MSDs. Assessment of RULA showed that most of female workers task needs further investigation and required change. As female participation was more in weeding activity and they have to adopt continuous squatting posture and using of primitive hand weeding tool which leads to risk of task. Again REBA assessment showed that workers working in unnatural posture which can develop the possibilities of postural MSDs, therefore task needs further investigation and required change. However, women workers of vegetable cultivating specially doing weeding activity suffer from various musculoskeletal problems as well as health risk and injuries. Therefore some changes may be required in terms of developing and implementing improved agricultural technology and ergonomics intervention are required to make farmers aware about work related injuries in agriculture field. 


\section{Recommendation}

The study recommends some new and improved technologies can be introduced such as angular khurpi, standing rake etc for weeding activity while doing vegetable cultivation. Some training programme with improved tools and technologies and awareness programme on occupational health and safety of workers are also recommended. Additionally, these data can be used as a basis for technology designing for weeding activity of vegetable cultivation.

\section{Acknowledgement}

This is a part of the project of AICRP-Home Science (FRM component), funded by CIWA, ICAR, Bhubaneswar.

\section{References}

Ansari N.A. and Sheikh M. J (2014) Evaluation of work Posture by RULA and REBA: A Case Study, IOSR Journal of Mechanical and Civil Engineering. 11 (4):18-23.

Dalkilinç M, Bumin G, Kayihan H (2002) The effects of ergonomic training and preventive physiotherapy in musculoskeletal pain. The Pain Clinic. 14(1):75-9.

Grooten WJA, Mulder M, Josephson M, Alfredsson L, Wiktorin C (2007) The influence of work-related exposures on the prognosis of neck/shoulder pain. European Spine Journal, 16(12):20832091.

Gupta, M.P (2005) Empowerment of women in Agriculture. Daily Excelsior. 28 May, 2006

Hignett, S. and McAtamney, L. (2000) 'Rapid entire body assessment (REBA). Applied Ergonomics. 31(2):201.

Kumari, Anuradha Ranjan and Laxmikant (2015) Participation of rural women in vegetable production. Adv. Res. J. Soc. Sci. 6 (2): 258-260.

McAtamney L, Corlett N (1993) RULA: A survey method for the investigation of work-related upper limb disorders. Applied Ergonomics. 24: 91-99.

Rao, E. K. (2006) Role of Women in Agriculture: A Micro level study. Journal of Global Economy. 2(2):107118.

Mahendra Dev, S. (2011) Small Farmers in India: Challenges and Opportunities, Emerging Economics Research Dialogue Beijing, China, 14-15 Nov.

Solomon RDNJ, Roytre Christopher Laloo and Mishra Bhanu Prakash (2006) Traditional agricultural practices in Meghalaya, North East India. Indian Journal of Traditional Knowledge. 5(1):7-18.

Sudharani, P. and Raju, V.T. (1991) Participation of women in agricultural operations. Indian J of Ext. Edu. 28 (1 and 2): 54-59.

Yusuf M, Adiputra N, Sutjana IDP, Tirtayasa K (2016) The improvement of work posture using rapid upper limb assessment: Analysis to decrease subjective disorders of strawberry farmers in Bali. International Research Journal of Engineering, IT and Scientific Research, 2(9): 1-8.

\section{How to cite this article:}

Swapnali Borah and Nilakshi Borah. 2020. Ergonomic Assessment of Upper Limbs of Workers Involved in Vegetable Cultivation. Int.J.Curr.Microbiol.App.Sci. 9(05): 3201-3207. doi: https://doi.org/10.20546/ijcmas.2020.905.380 